\title{
Supporting Information: Optimized production of Fc fusion proteins by sortase enzymatic ligation
}

Kyle D. Apley ${ }^{1}$, Amy D. Laflin ${ }^{1}$, Stephanie N. Johnson ${ }^{1}$, Noora Batrash ${ }^{2}$, J. Daniel Griffin ${ }^{1}$,

Cory J. Berkland ${ }^{1,2,3}$, Brandon J. DeKosky ${ }^{1,2,3,4,5 *}$

${ }^{1}$ Department of Pharmaceutical Chemistry, University of Kansas, Lawrence, KS 66045, United

States

${ }^{2}$ Department of Chemical and Petroleum Engineering, University of Kansas, Lawrence, Kansas

66045, United States

${ }^{3}$ Bioengineering Graduate Program, University of Kansas, Lawrence, Kansas 66045

${ }^{4}$ Department of Chemical Engineering, Massachusetts Institute of Technology, Cambridge, MA

02142

${ }^{5}$ The Ragon Institute of MGH, MIT, and Harvard, Cambridge, MA 02139

\section{Corresponding Author}


Brandon J. DeKosky* - 400 Technology Square, Room 1020, Cambridge, MA 02139, Email:

dekosky@mit.edu

\section{SUPPLEMENTARY MATERIALS AND METHODS}

\section{Engineered hIgG1 plasmid preparation}

Plasmids were prepared by custom gene synthesis and cloning (GenScript). The engineered antibody heavy chain (HC) was built on the human IgG1 G1m1 allotype sequence (Figure 1A, Figure S1) and was inserted into a BRS_hIgG1 vector using the 5' restriction site Age1 and the 3' restriction site BgIII. ${ }^{1}$ The light chain (LC) sequence (Figure S1) was inserted into a BRS_hlambda vector using the $5^{\prime}$ 'restriction site Age 1 and the $3^{\prime}$ restriction site Xho1. ${ }^{1}$ The $\mathrm{HC}$ and LC variable region sequences originate from an anti-Zika human $\operatorname{IgG1}(\mathrm{mAb} 18)$ and were selected based on favorable expression yields in BRS_hIgG1 expressed with Expi293 cells. ${ }^{2}$ DNA transformation for plasmid preparation was performed with MegaX DH10B T1R Electrocomp Cells (Fisher Scientific) then plated on 2XYT agar plates with $0.5 \mathrm{mg} / \mathrm{mL}$ kanamycin for $\mathrm{HC}$ plasmids and $0.5 \mathrm{mg} / \mathrm{mL}$ ampicillin for LC plasmids. Following incubation at $37{ }^{\circ} \mathrm{C}$ for 16 hours, cells were scraped from the surface of the plates using TE buffer (Bio Basic) and DNA was 
isolated using a ZymoPURE II Plasmid Maxiprep kit (Zymo Research). The DNA was then sterilized in $0.22 \mu \mathrm{m}$ Costar Spin-X centrifuge tube filters (Corning) and stored at $-20{ }^{\circ} \mathrm{C}$.

\section{HPLC protocol development for Fc-FITC analysis}

We used an ammonium bicarbonate buffer and methanol mobile phase system instead of acidified water and acetonitrile to maximize the molar extinction coefficient of $\mathrm{G}_{3}$-FITC at 490

$\mathrm{nm}$ and reduce the limit of quantification. Acidic conditions and acetonitrile promote fluorescein

to exist as a neutral spiro-lactone, with negligible absorbance in the visible spectrum (Figure

S4A). ${ }^{3}$ The HPLC method (Figure S4D) produced a linear response over the concentrations of $\mathrm{G}_{3}$-FITC tested and cleanly resolved Fc-FITC from excess $\mathrm{G}_{3}$-FITC (Figure 3B, Figure S4B).

For the secondary screen, the HPLC sample preparation method was modified by adding $0.005 \%$

Tween 20 to reduce non-specific protein adsorption to the polypropylene low-volume HPLC

vials, which may have contributed to reduced yield in initial screens. The results of the $1 \mathrm{~mol} \%$,

16 eq. $\mathrm{G}_{3}$-FITC, $50 \mu \mathrm{M}$ Fc reaction in subsequent screens suggested that $0.005 \%$ Tween 20

reduced non-specific absorption during prolonged wait times prior to analysis, and with higher

consistency than in the primary screen. 


\section{Sortase expression and purification}

Sortase A pentamutant in pET29 ${ }^{4}$ was a kind gift from Dr. David Liu (Addgene plasmid \# 75144 ; http://n2t.net/addgene:75144 ; RRID:Addgene_75144) and was transformed into chemically competent BL21 DE3 E. coli following the manufacturer's recommended protocol. Expression was performed according to the following procedure. Two $50 \mathrm{ml}$ cultures of autoclaved LB media with $50 \mu \mathrm{g} / \mathrm{ml}$ kanamycin sulfate in $125 \mathrm{ml}$ baffled shake flasks were inoculated and incubated overnight at 37C and 200 RPMs. The next day, 4x1L expression cultures of LB media with $50 \mu \mathrm{g} / \mathrm{ml}$ kanamycin sulfate in $2.8 \mathrm{~L}$ baffled shake flasks were inoculated with $10 \mathrm{ml}$ of overnight growth culture and incubated at 37C and 160 RPMs for 3-4 hours until an OD600nm of 0.75 was reached. Expression was induced by adding $0.5 \mathrm{mM} \mathrm{IPTG.}$ After 4 hours, the E. coli was harvested by transferring $500 \mathrm{ml}$ of media each into $750 \mathrm{ml}$ centrifuge bottle and spun down in a swinging bucket centrifuge at 4,000xg for 45 minutes at $4 \mathrm{C}$.

Each pellet was suspended in $15 \mathrm{ml}$ of lysis buffer (10 $\mathrm{mM}$ Tris, $30 \mathrm{mM} \mathrm{NaCl}, \mathrm{pH}$ 7.5), combined into a glass jar, and homogenized by a probe homogenizer at $85 \%$ intensity for 4 minutes while on ice. The suspension was centrifuged at $10,000 \times \mathrm{g}$ for 10 minutes at $20 \mathrm{C}$. The 
supernatant was filtered with a 0.22 um syringe filter prior to purification by nickel-immobilized affinity metal chromatography on a $5 \mathrm{ml}$ GE HisTrap HP column according to the manufacturer's protocol. Fractions containing eSrtA (5M) were identified by SDS-PAGE (Figure S3), buffer exchanged to tris-buffered saline $\mathrm{pH} 7.5$, then formulated at $1.8 \mathrm{mg} / \mathrm{ml}(0.1 \mathrm{mM})$ in $40 \mathrm{mM}$ Tris $\mathrm{pH}$ 7.5, $120 \mathrm{mM} \mathrm{NaCl}, 0.04 \%$ Tween-20, and 20\% glycerol before being sterile filtered and frozen at $-80 \mathrm{C}$ in aliquots.

\section{Synthesis of $\mathrm{G}_{3}$-FITC}

Fmoc-triglycine was synthesized using a method similar to that reported for Fmoc-glycine. ${ }^{5}$

Briefly, $500 \mathrm{mg}$ of triglycine was dissolved in $3 \mathrm{ml}$ of aqueous $10 \%$ sodium carbonate in a $50 \mathrm{ml}$ round-bottom flask $(\mathrm{RBF})$ in an ice bath. To the flask, a solution of $684 \mathrm{mg}$ of FMOC-Cl in $6 \mathrm{ml}$ of 1,4 dioxane was added. The reaction was stirred for 15 minutes on ice, warmed to room temperature, stirred for 90 minutes, then mixed with $150 \mathrm{ml}$ water and extracted twice with diethyl ether. $15 \mathrm{ml}$ of $1 \mathrm{M} \mathrm{HCl}$ was added to the separated aqueous phase then extracted $4 \mathrm{x}$ with $100 \mathrm{ml}$ ethyl acetate. The organic extract was washed with $1 \mathrm{x} 40 \mathrm{ml}$ acidified brine then evaporated to yield a white powder (518 mgs, $48 \%$ yield). Mass determination: MALDI-TOF 
MS. Expected MW $=411.41 ;$ found $=412.67[\mathrm{M}+\mathrm{H}]^{+} .{ }^{1} \mathrm{H}$ NMR $\left(500 \mathrm{MHz}, \mathrm{DMSO}-d_{6}\right) \delta 8.23-$ $8.14(\mathrm{~m}, 1 \mathrm{H}), 7.90(\mathrm{~d}, J=7.6 \mathrm{~Hz}, 1 \mathrm{H}), 7.73(\mathrm{~d}, J=7.5 \mathrm{~Hz}, 1 \mathrm{H}), 7.59(\mathrm{t}, J=6.1 \mathrm{~Hz}, 1 \mathrm{H}), 7.42(\mathrm{t}, J$ $=7.4 \mathrm{~Hz}, 1 \mathrm{H}), 7.34(\mathrm{t}, J=7.4 \mathrm{~Hz}, 1 \mathrm{H}), 4.30(\mathrm{~d}, J=7.0 \mathrm{~Hz}, 1 \mathrm{H}), 4.27-4.19(\mathrm{~m}, 1 \mathrm{H}), 3.76(\mathrm{dd}, J$ $=5.9,4.0 \mathrm{~Hz}, 2 \mathrm{H}), 3.68(\mathrm{~d}, J=6.1 \mathrm{~Hz}, 1 \mathrm{H}) .{ }^{13} \mathrm{C}$ NMR (500 MHz, DMSO- $\left.d_{6}\right): \delta$ 41.1, 42.2, 44.0, 47.1, 66.2, 120.6, 125.7, 127.6, 128.1, 141.2, 144.3, 157.0, 169.6, 169.9, 171.6 (Figure S9, S10).

Fmoc-triglycine-PEG3-amine was synthesized by first dissolving $100 \mathrm{mg}$ of Fmoc-triglycine in dry DMF in a flame-dried $8 \mathrm{ml}$ glass vial. Second, $93.5 \mathrm{mgs}$ of amino-PEG3-amine was added immediately followed by $138.7 \mathrm{mgs}$ of HATU. The reaction was stirred at room temperature for 10 minutes then quenched by the addition of $10 \mathrm{ml}$ of $50 \mathrm{mM} \mathrm{HCl}$. Precipitate was removed by vacuum filtration through a 0.22 um nylon filter prior to purification by Prep-LC using a 10minute 32-37\%B gradient on a Waters XBridge Prep C18 5um OBD 19x250mm column with a flow rate of $14 \mathrm{ml} / \mathrm{min}$, where mobile phase A is water with $0.05 \%$ TFA and mobile phase B is acetonitrile with $0.05 \%$ TFA. Acetonitrile was removed from the product fraction by rotary evaporation prior to freezing at $-80 \mathrm{C}$ and lyophilization to yield the product as a thick oil (60 mgs, $41 \%$ yield). Mass determination: MALDI-TOF MS. Expected MW $=585.28$; found $=$ $586.47[\mathrm{M}+\mathrm{H}]^{+} .{ }^{1} \mathrm{H}$ NMR $\left(500 \mathrm{MHz}, \mathrm{DMSO}-d_{6}\right): \delta 8.17(\mathrm{t}, J=5.7 \mathrm{~Hz}, 2 \mathrm{H}), 8.12(\mathrm{t}, J=5.9 \mathrm{~Hz}$, 
2H), $7.90(\mathrm{~d}, J=7.5 \mathrm{~Hz}, 4 \mathrm{H}), 7.83(\mathrm{t}, J=5.8 \mathrm{~Hz}, 2 \mathrm{H}), 7.72(\mathrm{~d}, J=7.5 \mathrm{~Hz}, 5 \mathrm{H}), 7.59(\mathrm{t}, J=6.1$

$\mathrm{Hz}, 3 \mathrm{H}), 7.43(\mathrm{t}, J=7.5 \mathrm{~Hz}, 4 \mathrm{H}), 7.34(\mathrm{t}, J=7.4 \mathrm{~Hz}, 4 \mathrm{H}), 6.58(\mathrm{~s}, 1 \mathrm{H}), 4.30(\mathrm{~d}, J=7.0 \mathrm{~Hz}, 3 \mathrm{H})$,

$4.24(\mathrm{t}, J=7.0 \mathrm{~Hz}, 3 \mathrm{H}), 3.75(\mathrm{~d}, J=5.7 \mathrm{~Hz}, 3 \mathrm{H}), 3.68(\mathrm{t}, J=5.5 \mathrm{~Hz}, 6 \mathrm{H}), 3.62-3.54(\mathrm{~m}, 9 \mathrm{H})$,

$3.54-3.47(\mathrm{~m}, 7 \mathrm{H}), 3.40(\mathrm{t}, J=6.1 \mathrm{~Hz}, 4 \mathrm{H}), 3.21(\mathrm{q}, J=6.0 \mathrm{~Hz}, 4 \mathrm{H}), 2.98(\mathrm{~h}, J=5.7 \mathrm{~Hz}, 4 \mathrm{H})$.

${ }^{13} \mathrm{C}$ NMR (500 MHz, DMSO- $\left.d_{6}\right): \delta$ 42.4, 42.6, 44.0, 47.1, 66.2, 67.1, 69.4, 70.0, 70.1, 70.1, 70.2,

120.6, 125.7, 127.6, 128.1, 141.2, 144.3, 157.01, 158.3, 158.6, 159.2, 169.3, 169.6, 170.1 (Figure

S11, S12).

Triglycine-PEG3-FITC was synthesized by dissolving 60 mgs of Fmoc-trigylcine-PEG3-

amine in $940 \mu \mathrm{L}$ of dry DMF in a flame-dried $8 \mathrm{ml}$ glass vial. Second, $50 \mathrm{mgs}$ of fluorescein

isothiocyanate (FITC) and $44.7 \mu \mathrm{l}$ of dry N,N-diisopropylethylamine (DIPEA) were added, then

the reaction was stirred for 5 minutes. Third, $44.1 \mu \mathrm{l}$ of isopropylamine was added and the

reaction was stirred for 5 minutes. Next, $257 \mu \mathrm{l}$ of piperidine was added and the reaction was

stirred for 5 minutes before dilution with $8 \mathrm{mls}$ of DMSO and acidification with $500 \mu \mathrm{l}$ of formic

acid prior to purification by Prep-LC using a 10-minute 20-40\%B gradient on a Waters XBridge

Prep C18 5 um OBD 19x250mm column with a flow rate of $14 \mathrm{ml} / \mathrm{min}$ where mobile phase A is

water with $0.05 \%$ TFA and mobile phase B is acetonitrile with 0.05\% TFA. Bulk solvent was 
removed from the product fraction by rotary evaporation prior to drying under high vacuum (10 mTorr) overnight to yield a dark orange oil (65 mgs, $86 \%$ yield). Purity: HPLC, > 95\%. Mass determination: MALDI-TOF MS. Expected MW $=752.8$; found $=753.3[\mathrm{M}+\mathrm{H}]^{+} .{ }^{1} \mathrm{H}$ NMR $(500$ MHz, DMSO- $\left.d_{6}\right): \delta 10.09$ (s, $\left.1 \mathrm{H}\right), 8.60(\mathrm{t}, J=5.7 \mathrm{~Hz}, 1 \mathrm{H}), 8.28(\mathrm{~s}, 1 \mathrm{H}), 8.23(\mathrm{t}, J=5.9 \mathrm{~Hz}, 1 \mathrm{H})$, $8.14(\mathrm{~s}, 1 \mathrm{H}), 7.98(\mathrm{~s}, 2 \mathrm{H}), 7.94(\mathrm{q}, J=5.4 \mathrm{~Hz}, 2 \mathrm{H}), 7.75(\mathrm{~d}, J=8.4 \mathrm{~Hz}, 1 \mathrm{H}), 7.19(\mathrm{~d}, J=8.3 \mathrm{~Hz}$, 1H), $6.68(\mathrm{~d}, J=2.3 \mathrm{~Hz}, 2 \mathrm{H}), 6.65-6.54(\mathrm{~m}, 4 \mathrm{H}), 3.97(\mathrm{~s}, 1 \mathrm{H}), 3.85(\mathrm{~d}, J=5.7 \mathrm{~Hz}, 2 \mathrm{H}), 3.71(\mathrm{~d}$, $J=5.9 \mathrm{~Hz}, 3 \mathrm{H}), 3.65-3.55(\mathrm{~m}, 7 \mathrm{H}), 3.55-3.47(\mathrm{~m}, 4 \mathrm{H}), 3.41(\mathrm{t}, J=6.0 \mathrm{~Hz}, 2 \mathrm{H}), 3.22(\mathrm{q}, J=$ $5.9 \mathrm{~Hz}, 2 \mathrm{H}) .{ }^{13} \mathrm{C}$ NMR (500 MHz, DMSO- $\left.d_{6}\right): \delta 22.7,42.3,42.4,44.2,49.1,55.5,68.9,69.5$, 70.1, 70.1, 70.2, 70.2, 102.7, 110.2, 113.1, 114.9, 116.8, 117.2, 129.5, 141.8, 152.4, 158.6 ,158.9, 160.0, 166.7, 168.9, 169.0, 169.1, 181.0 (Figure S13, S14). 
Engineered Antibody HC Inserted sequence in BRS_hlgG1

ACTGCAACCGGTGTACATTCTCAGCTGCAGCTGCAGGAGAGCGGACCAGGACTGGTGAAGCCATCT GAGACCCTGAGCCTGACCTGCACAGTGAGCGGCGGCTCCATCAGCTCCTCTAGCTACTATTGGGGAT GGATCAGGCAGCCACCTGGCAAGGGACTGGAGTGGATCGGCTCCATCTACTATAGCGGCTCCACCT ACTATAACCCCTCTCTGAAGAGCCGCGTGACCATCTCCGTGGACACATCTAAGAATCAGTTCAGCCTG AAGCTGTCCTCTGTGACCGCCGCCGATACAGCCGTGTACTATTGCGCCCGGCACAGATCCTTCCCTT ACAGCTCCTCTAGCTTTGACTATTGGGGCCAGGGCACCCTGGTGACAGTGTCCTCTGCCAGCACCAA GGGCCCATCCGTGTTTCCTCTGGCCCCAAGCTCCAAGTCTACCAGCGGAGGAACAGCCGCCCTGGG ATGTCTGGTGAAGGATTACTTCCCTGAGCCAGTGACAGTGTCCTGGAACTCTGGCGCCCTGACCAGC GGAGTGCACACATTTCCAGCCGTGCTGCAGTCTAGCGGCCTGTACTCCCTGTCCTCTGTGGTGACCG TGCCCAGCTCCTCTCTGGGCACCCAGACATATATCTGCAACGTGAATCACAAGCCCAGCAATACAAA GGTGGACAAGAAGGTGGAGCCTAAGTCCTGTGATAAGCTGGAGGTGCTGTTCCAGGGACCAACCCA CACATGCCCACCATGTCCAGCACCTGAGCTGCTGGGAGGACCTAGCGTGTTCCTGTTTCCTCCAAAG CCAAAGGACACCCTGATGATCTCTCGGACCCCTGAGGTGACATGCGTGGTGGTGGACGTGAGCCAC GAGGATCCAGAGGTGAAGTTTAACTGGTACGTGGATGGCGTGGAGGTGCACAATGCCAAGACAAAGC CTAGGGAGGAGCAGTACAACTCCACCTATCGCGTGGTGTCTGTGCTGACAGTGCTGCACCAGGACTG GCTGAACGGCAAGGAGTATAAGTGCAAGGTGTCCAATAAGGCCCTGCCAGCCCCCATCGAGAAGAC CATCTCTAAGGCAAAGGGACAGCCAAGGGAGCCTCAGGTGTACACACTGCCCCCTTCCAGAGACGA GCTGACCAAGAACCAGGTGTCTCTGACATGTCTGGTGAAGGGCTTCTATCCATCTGATATCGCCGTG GAGTGGGAGAGCAATGGCCAGCCCGAGAACAATTACAAGACCACACCACCCGTGCTGGACAGCGAT GGCTCCTTCTTTCTGTATAGCAAGCTGACCGTGGATAAGTCCCGGTGGCAGCAGGGCAACGTGTTTT CCTGTTCTGTGATGCACGAGGCCCTGCACAATCACTACACCCAGAAGAGCCTGTCCCTGTCTCCCGG CAAGGGAGGAGGAGGATCTGGAGGAGGAGGAAGCCTGCCTGAGACAGGCGGCCACCACCACCACC ACCACTGATGAGGATCCAGATCTGCT

\section{Antibody LC inserted sequence in BRS_h-lambda}

ACTGCAACCGGTGTACATTCTCAGTCTGTGCTGACTCAGCCGCCCTCAGTGTCTGGGGCCCCAGGG CAGAGGGTCACCATCTCCTGCACTGGGAGCAGCTCCAACATCGGGGCAGGTTATGATGTACACTGGT ACCAGCAGCTTCCAGGAACAGCCCCCAAACTCCTCATCTATGGTAACAGCAATCGGCCCTCAGGGGT CCCTGACCGATTCTCTGGCTCCAAGTCTGGCACCTCAGCCTCCCTGGCCATCACTGGGCTCCAGGCT GAGGATGAGGCTGATTATTACTGCCAGTCCTATGACAGCAGCCTGAGTGGTTATTATGTCTTCGGAAC TGGGACCAAGGTCACCGTCCTAGGTCAGCCCAAGGCTGCCCCCTCGGTCACTCTGTTCCCACCCTC GAGTGAGGA

Figure S1. Engineered human IgG1 HC (top) and LC (bottom) vector inserts. 


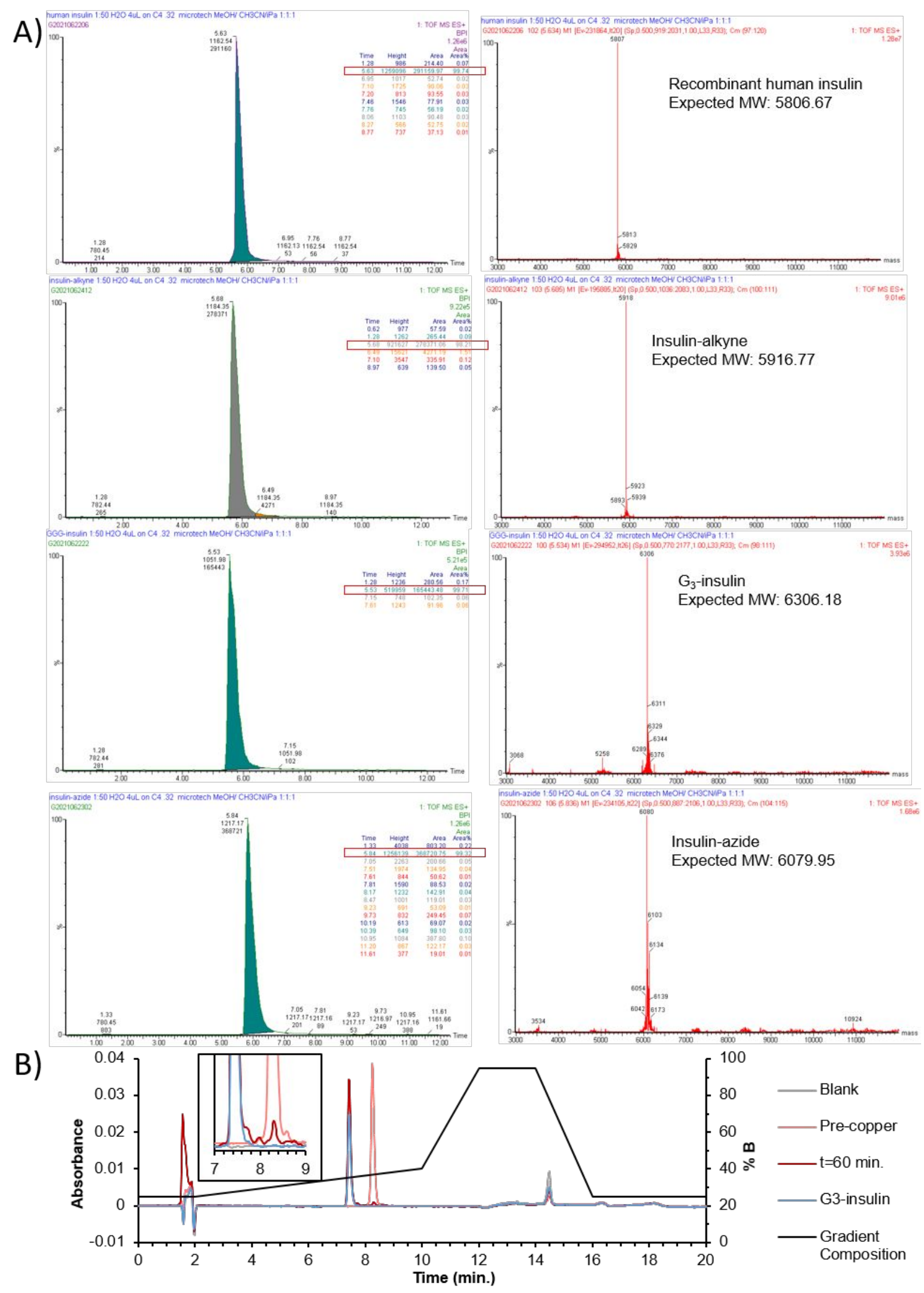


Figure S2. Analysis of functionalized insulins for sortase and SPAAC conjugation. A) Highresolution mass spectra of insulin, insulin-alkyne, $\mathrm{G}_{3}$-insulin, and insulin-azide, with peak identities indicated. B) HPLC chromatogram showing the conversion of insulin-alkyne (precopper) to $\mathrm{G}_{3}$-insulin ( $\mathrm{t}=60 \mathrm{~min}$.), along with purified $\mathrm{G}_{3}$-insulin. 


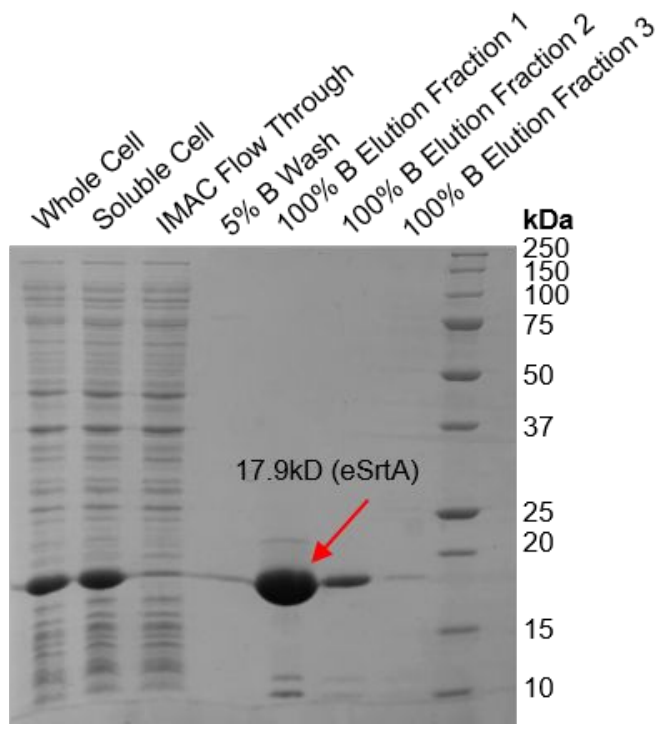

Figure S3. SDS-PAGE gel analysis of eSrtA (5M) expression and purification. 

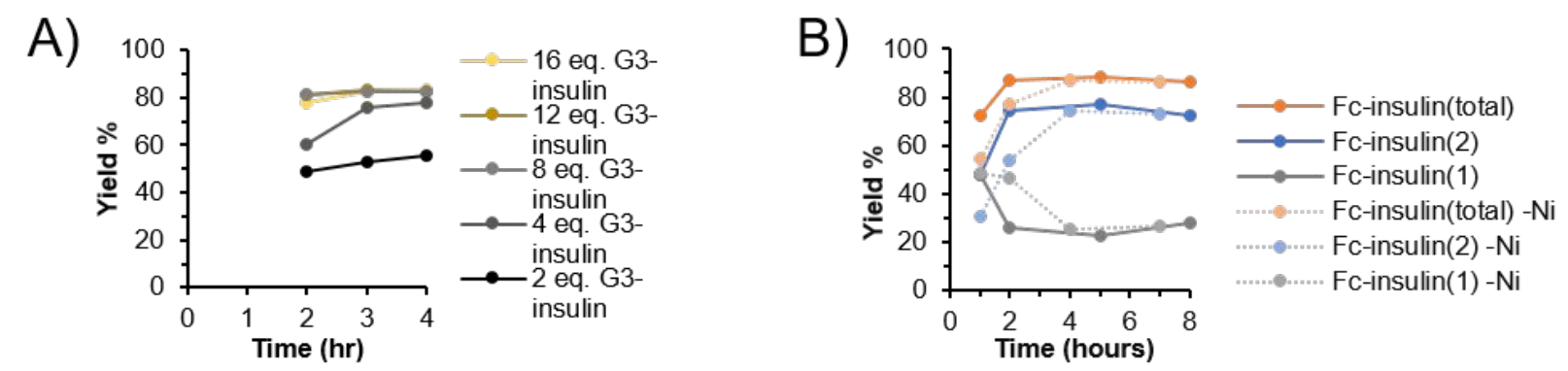

Figure S4. Additional direct sortase mediated ligation yield data. Yields are shown for additional reaction conditions of Fc-LPETGGH 6 and $\mathrm{G}_{3}$-insulin direct sortase ligation. A) Direct sortase condition screen of the equivalents of $\mathrm{G}_{3}$-insulin. Extended to 2-16 equivalents of $\mathrm{G}_{3}$-insulin.

Yields are on a per-Fc-monomer basis. B) Direct sortase method reaction time-profile of the 16 eq. $\mathrm{G}_{3}$-insulin method, with and without 2 equivalents of nickel. Fc-insulin ${ }_{\text {Mon }}$, Fc-insulin ${ }_{1}$, and Fc-insulin 2 yields are shown. 
A)
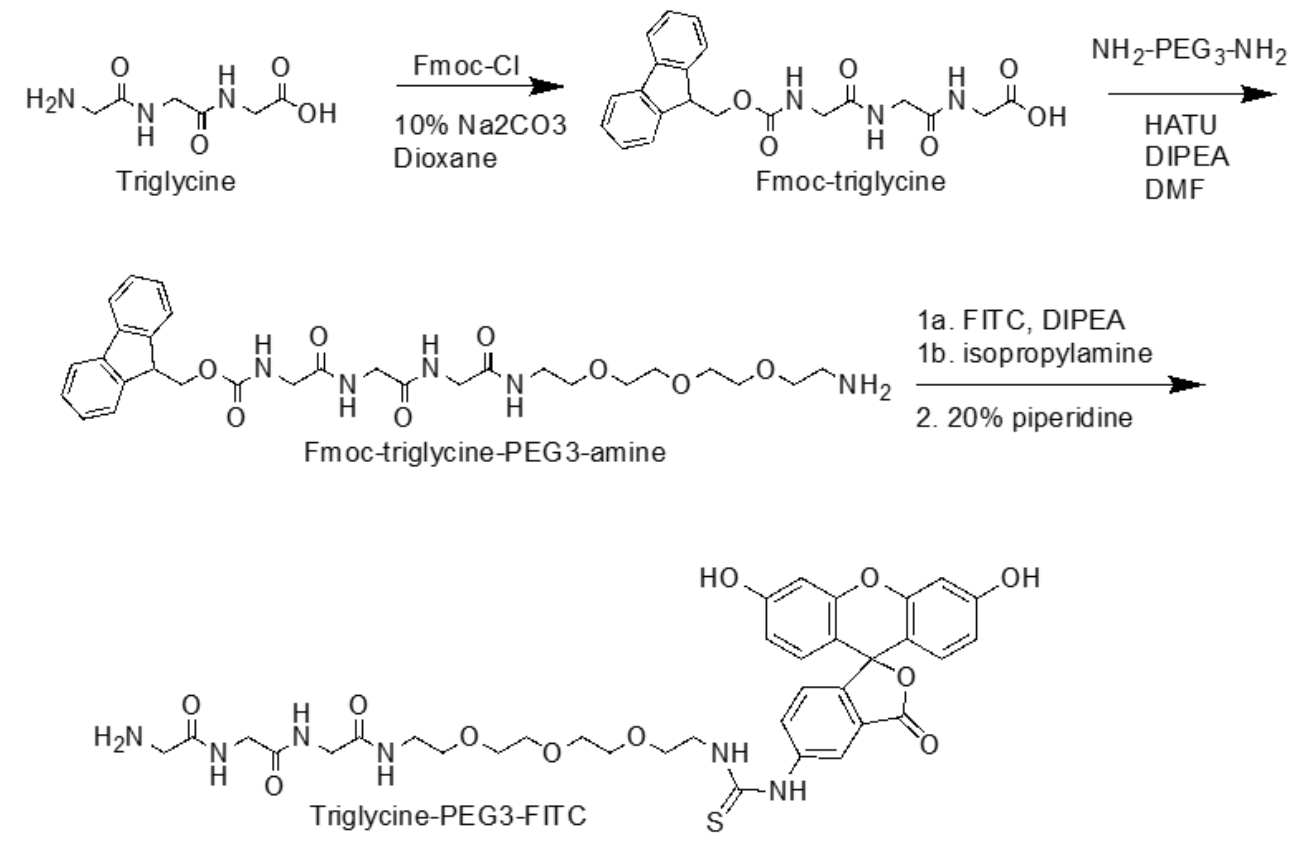

B)

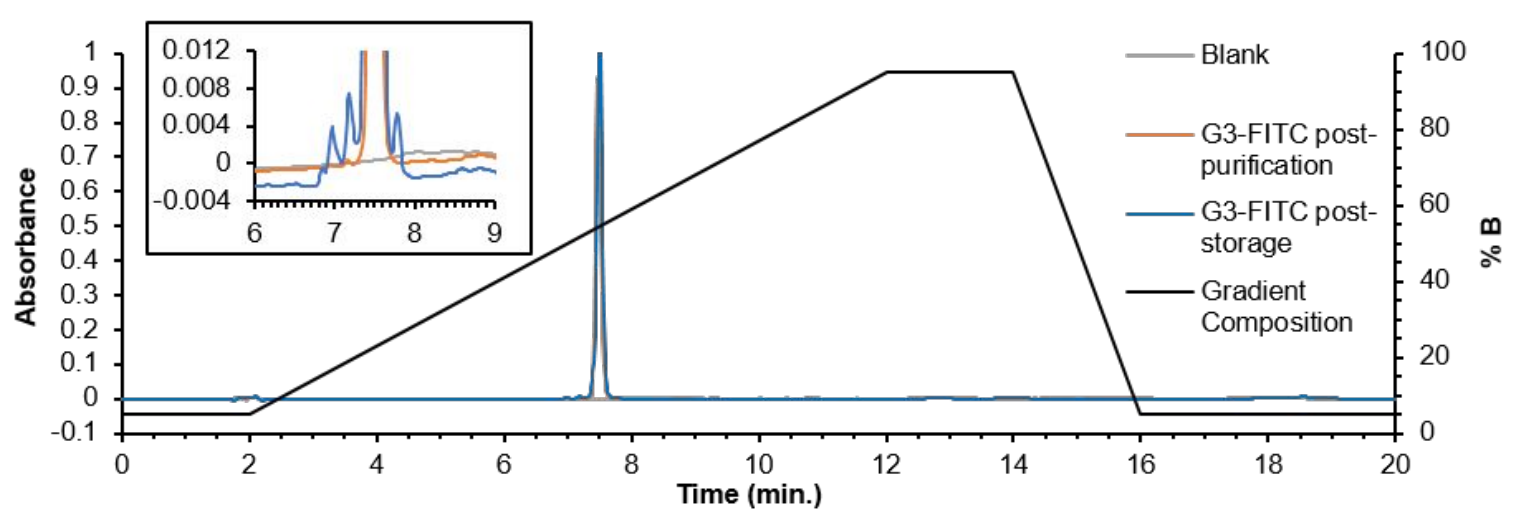

Figure S5. Overview of $\mathrm{G}_{3}$-FITC synthesis. A) Synthetic scheme for the synthesis of $\mathrm{G}_{3}$-FITC

(triglycine-PEG 3 -FITC). B) HPLC chromatogram of $\mathrm{G}_{3}$-FITC immediately post-purification by

RP-HPLC and at the time of the $\mathrm{G}_{3}$-FITC SML optimization experiment following storage as

$17.5 \mathrm{mg} / \mathrm{ml}$ aliquots in $50 \mathrm{mM}$ tris, $150 \mathrm{mM} \mathrm{NaCl} \mathrm{pH} 8.2$ buffer at $-80{ }^{\circ} \mathrm{C}$ for 3 months. 


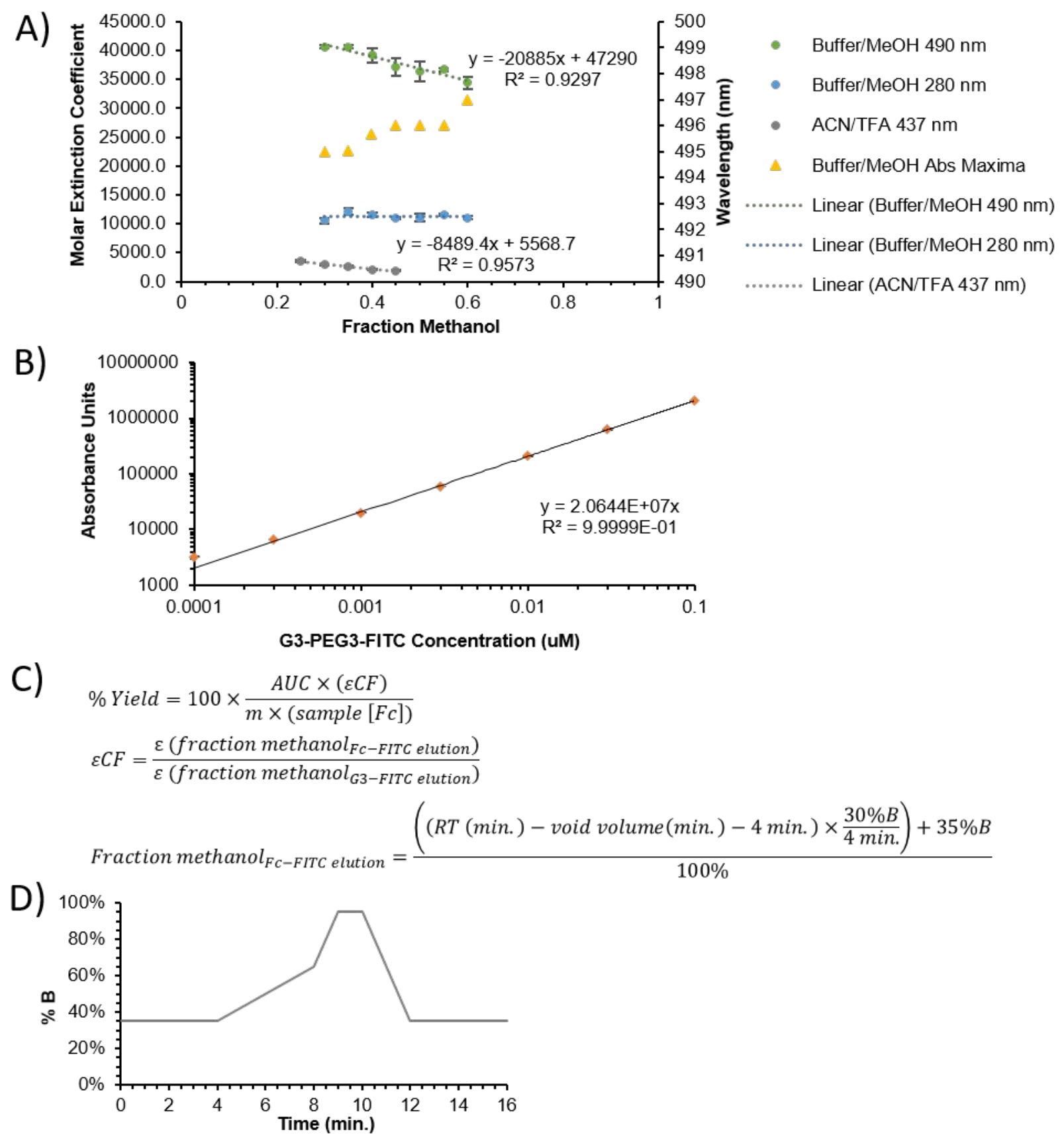

Figure S6. HPLC-based analysis of Fc-FITC sortase ligation reactions. HPLC was used to

quantify the products generated in the Fc-FITC optimization reactions. A) Determination of the

$\mathrm{G}_{3}$-FITC molar extinction coefficients in different mobile phase compositions. Each composition

was prepared in triplicate using gravimetric methods. B) Calibration curve of $\mathrm{G}_{3}$-FITC at 490 
nm. Each standard was prepared in triplicate using gravimetric methods. C) Calculations used to determine the Fc-LPETGGH 6 and $\mathrm{G}_{3}$-FITC sortase ligation yield based on HPLC analysis. AUC is the area under the curve for the Fc-FITC peak, $m$ is the slope of the calibration curve, and $\varepsilon C F$ is the correction factor accounting for the change in $\mathrm{G}_{3}$-FITC extinction coefficient based on mobile phase composition. D) Gradient used for HPLC analysis. 
A)

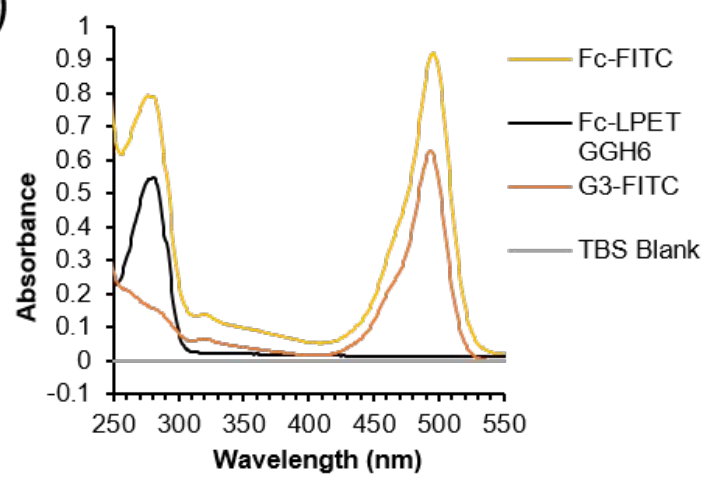

C)

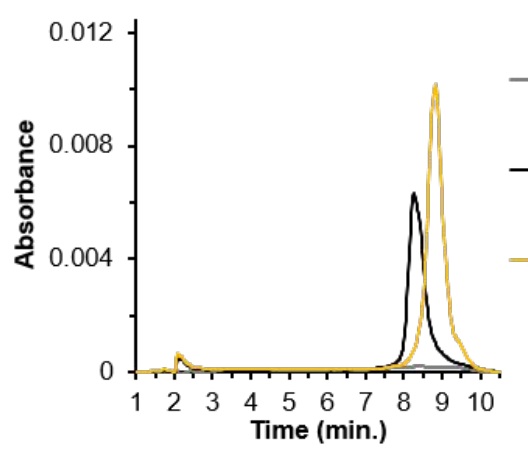

E)

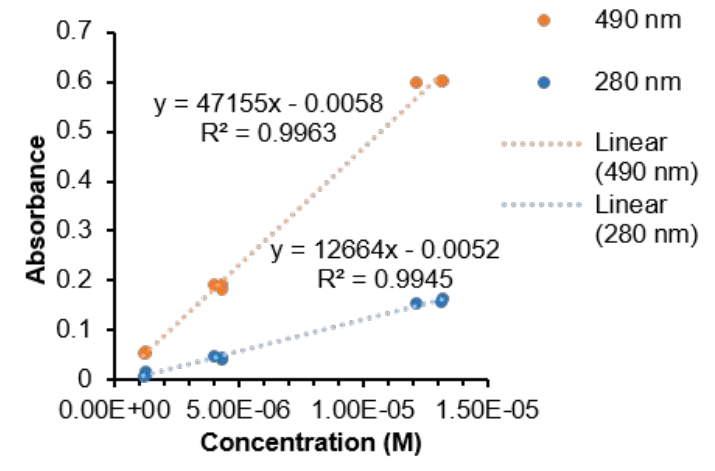

B)

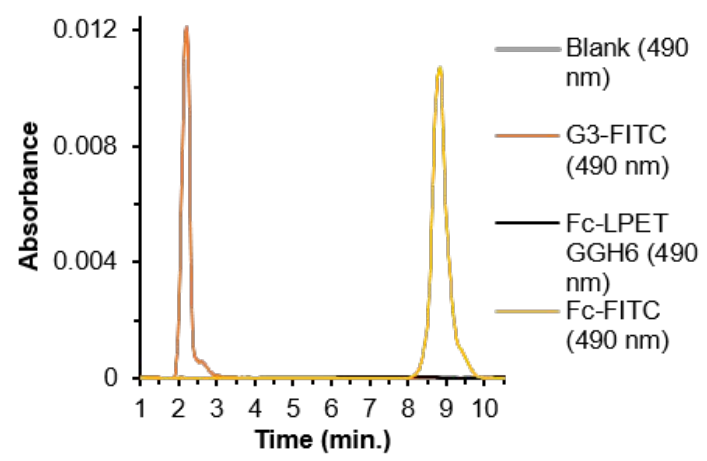

D)

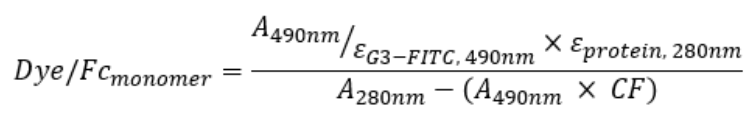

Correction Factor $(C F)=\frac{\varepsilon_{G 3-F I T C, 280 \mathrm{~nm}}}{\varepsilon_{G 3-F I T C, 490 \mathrm{~nm}}}$

Figure S7. Determination of the degree of dye-labeling on Fc-FITC to verify HPLC results for

Fc-LPETGGH ${ }_{6}$ and $\mathrm{G}_{3}$-FITC SML reactions. A) UV-Vis spectra for purified Fc-FITC compared with Fc-LPETGGH ${ }_{6}$ and $\mathrm{G}_{3}$-FITC. B) HPLC traces at $490 \mathrm{~nm}$ for purified Fc-FITC compared to Fc-LPETGGH ${ }_{6}$ and $\mathrm{G}_{3}$-FITC. C) HPLC traces at $280 \mathrm{~nm}$ for purified Fc-FITC compared to Fc- 
LPETGGH $_{6}$. D) Calculations for determining the degree of dye-labeling on purified Fc-FITC. E)

UV-Vis absorbance data for determining the molar extinction coefficients of $\mathrm{G}_{3}$-FITC. 
A)

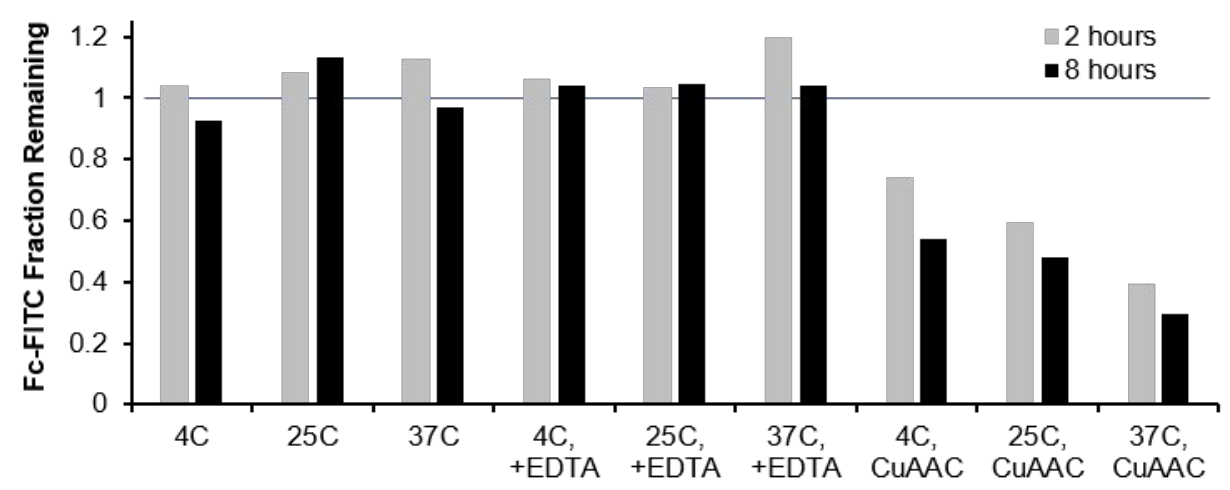

B)
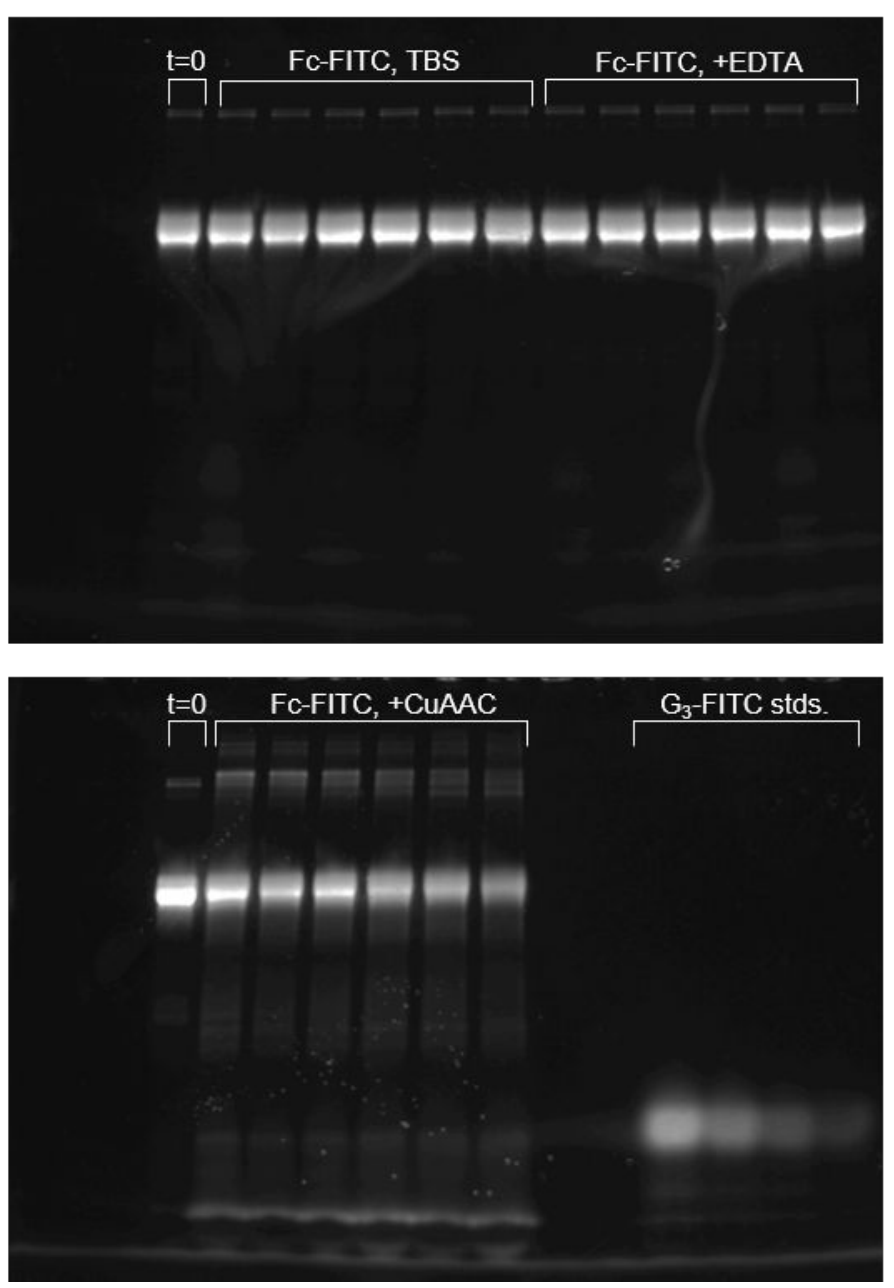

Figure S8. Stability study of Fc-FITC post-Protein A purification to determine the cause of product degradation. A) The Fc-FITC fraction remaining following the described condition. The 
$\mathrm{y}$-axis is standardized based off a $\mathrm{t}=0$ sample. $\mathrm{B})$ SDS-PAGE gels for the analysis of Fc-FITC.

Samples for each condition are arranged in the following order from left to right: $4{ }^{\circ} \mathrm{C} 2$ hours, 4

${ }^{\circ} \mathrm{C} 8$ hours, $25^{\circ} \mathrm{C} 2$ hours, $25^{\circ} \mathrm{C} 8$ hours, $37{ }^{\circ} \mathrm{C} 2$ hours, $37{ }^{\circ} \mathrm{C} 8$ hours. 


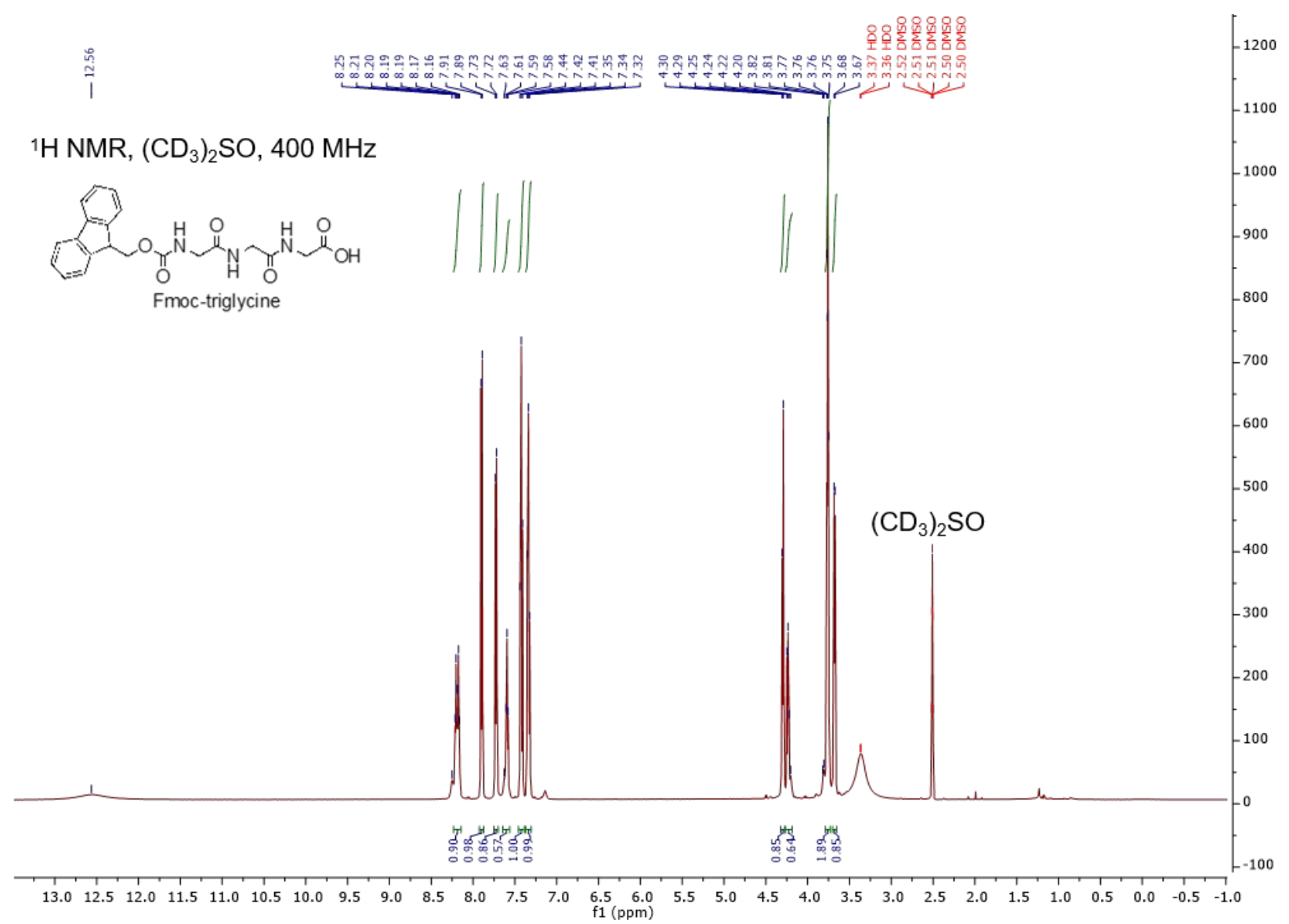

Figure S9. ${ }^{1} \mathrm{H}$ NMR spectrum of Fmoc-triglycine. 


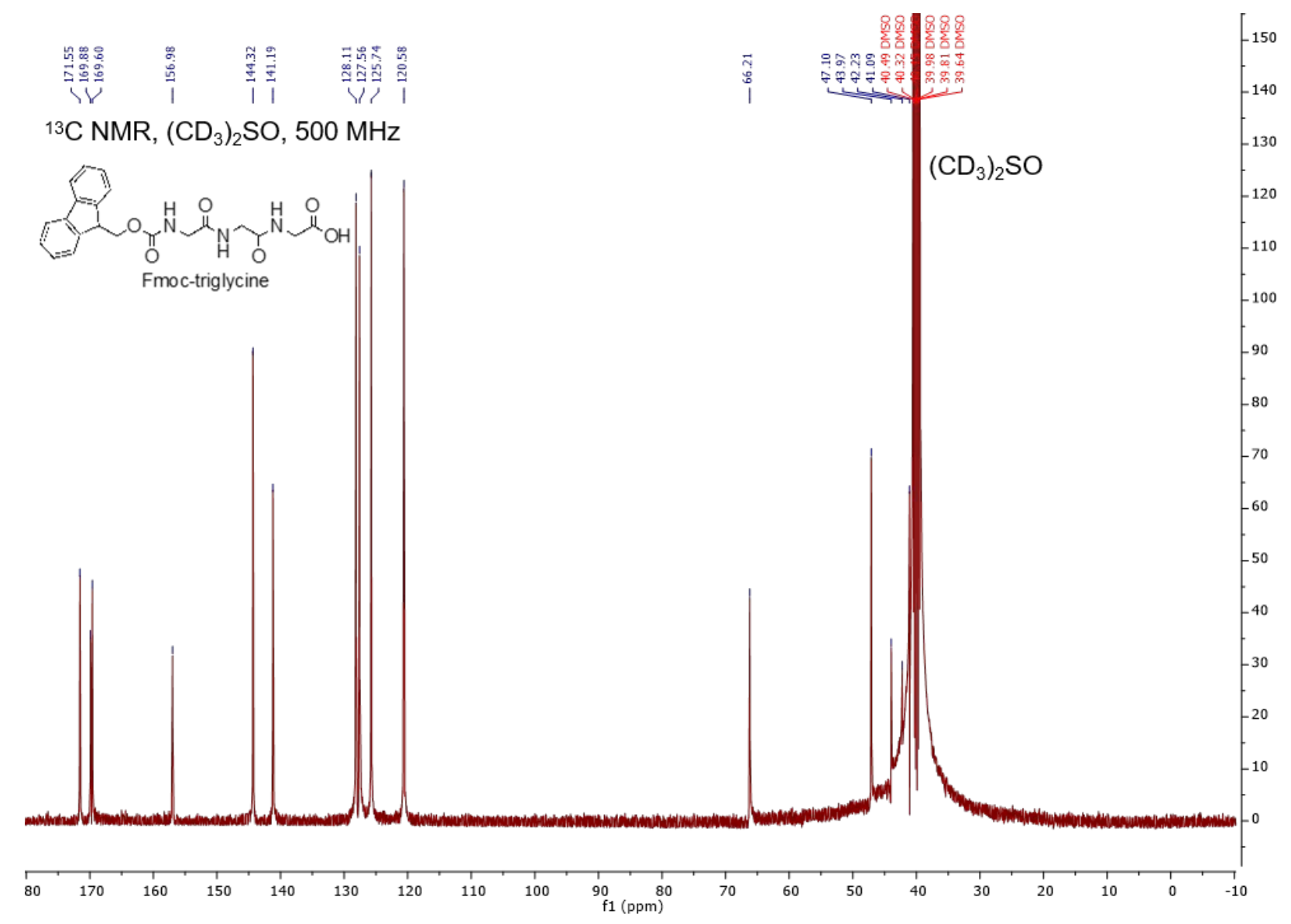

Figure S10. ${ }^{13} \mathrm{C}$ NMR spectrum of Fmoc-triglycine. 
$\underbrace{ \pm}$

${ }^{1} \mathrm{H} \mathrm{NMR},\left(\mathrm{CD}_{3}\right)_{2} \mathrm{SO}, 500 \mathrm{MHz}$

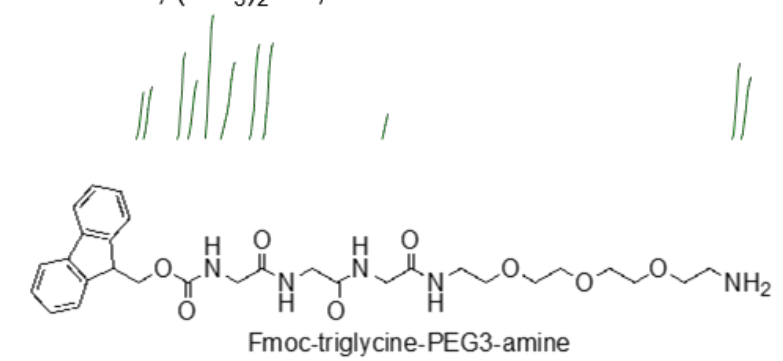

Fmoc-triglycine-PEG3-amine
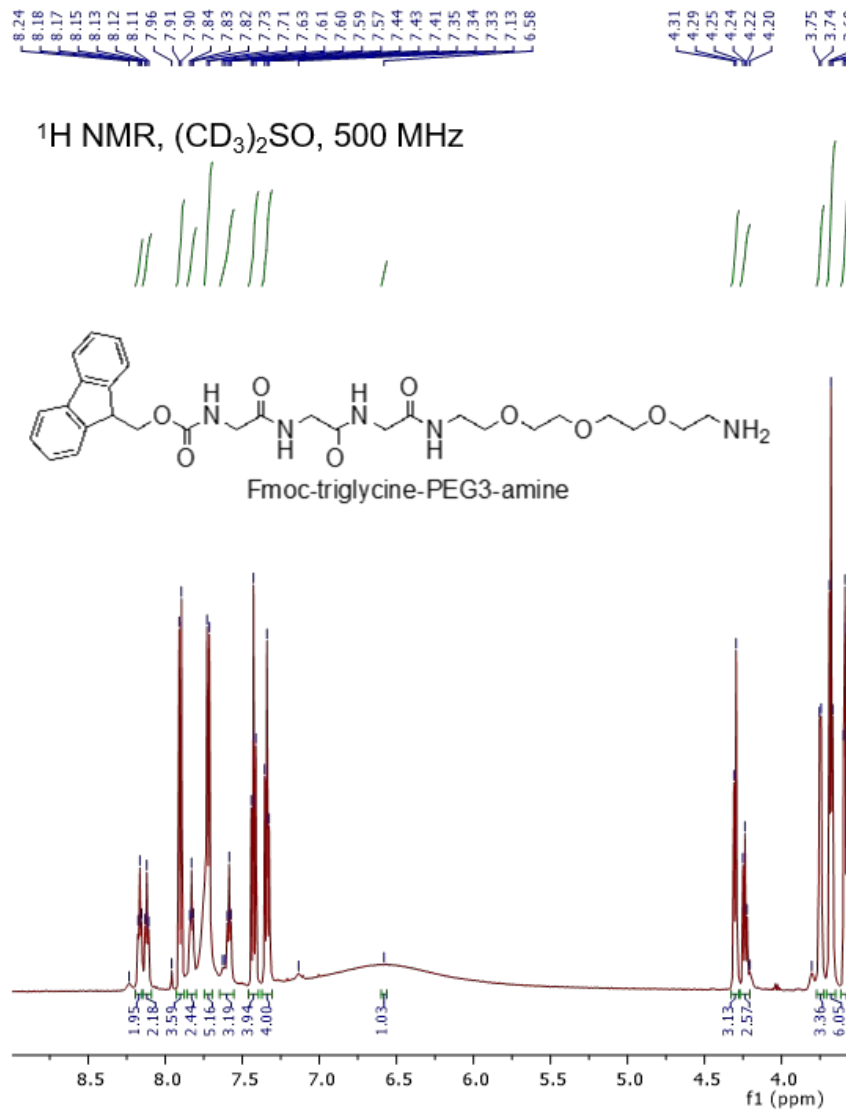

8 옹

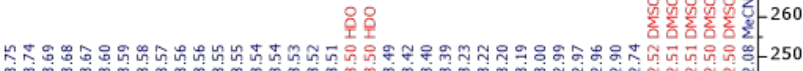
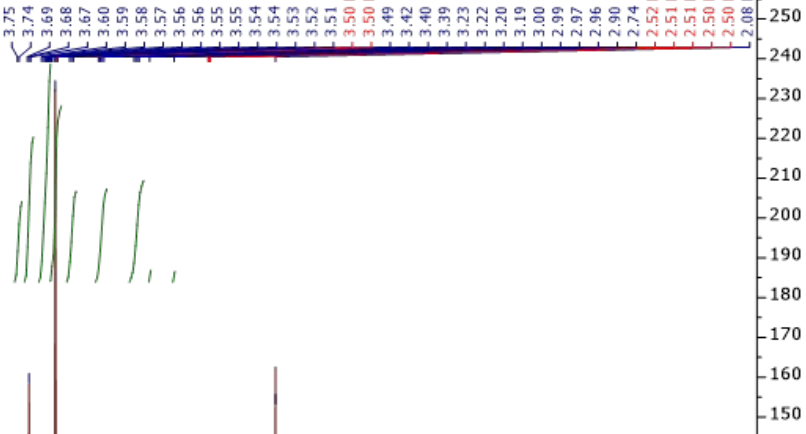


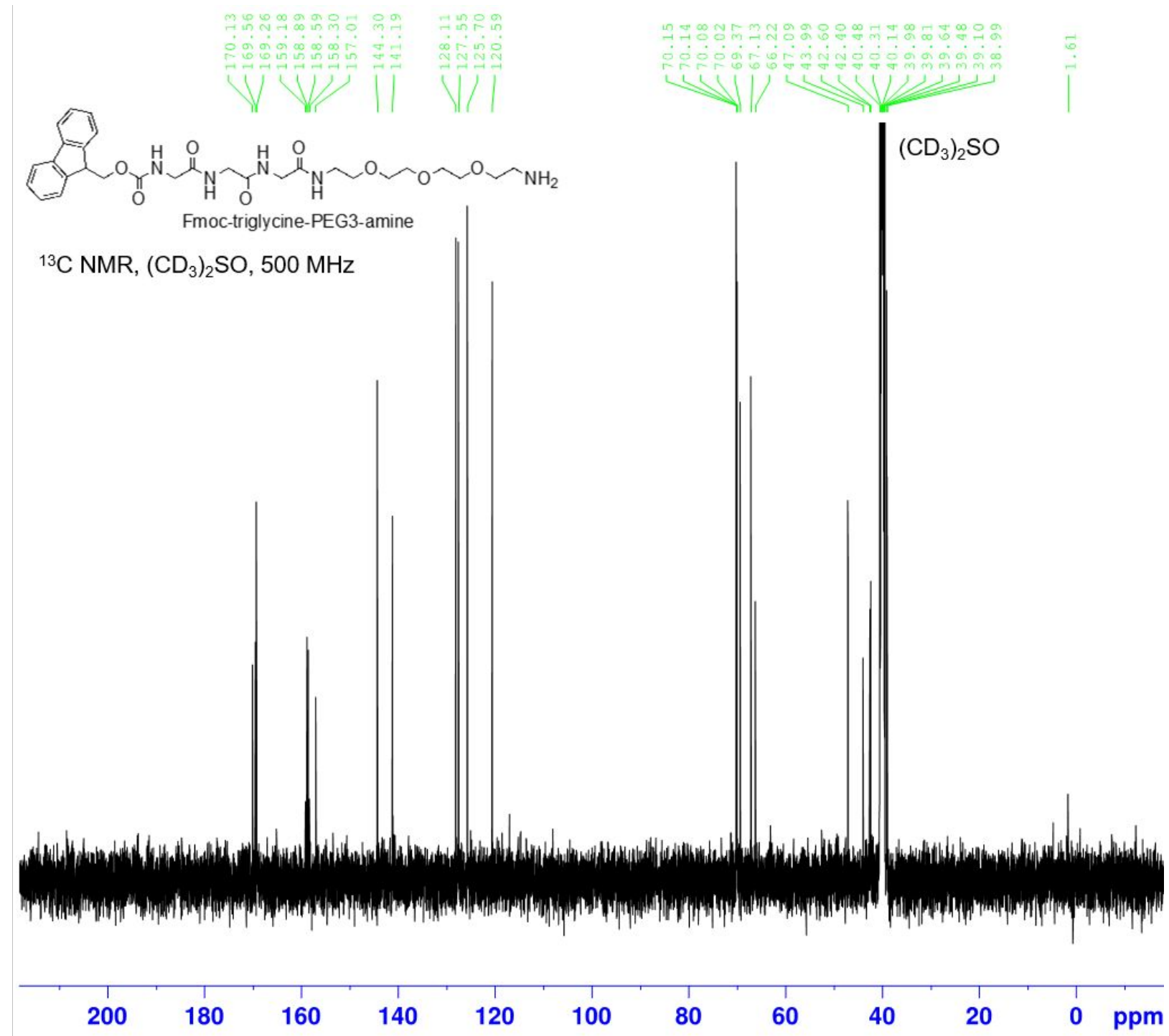

Figure S12. ${ }^{13} \mathrm{C}$ NMR spectrum of Fmoc-triglycine-PEG3-amine. 


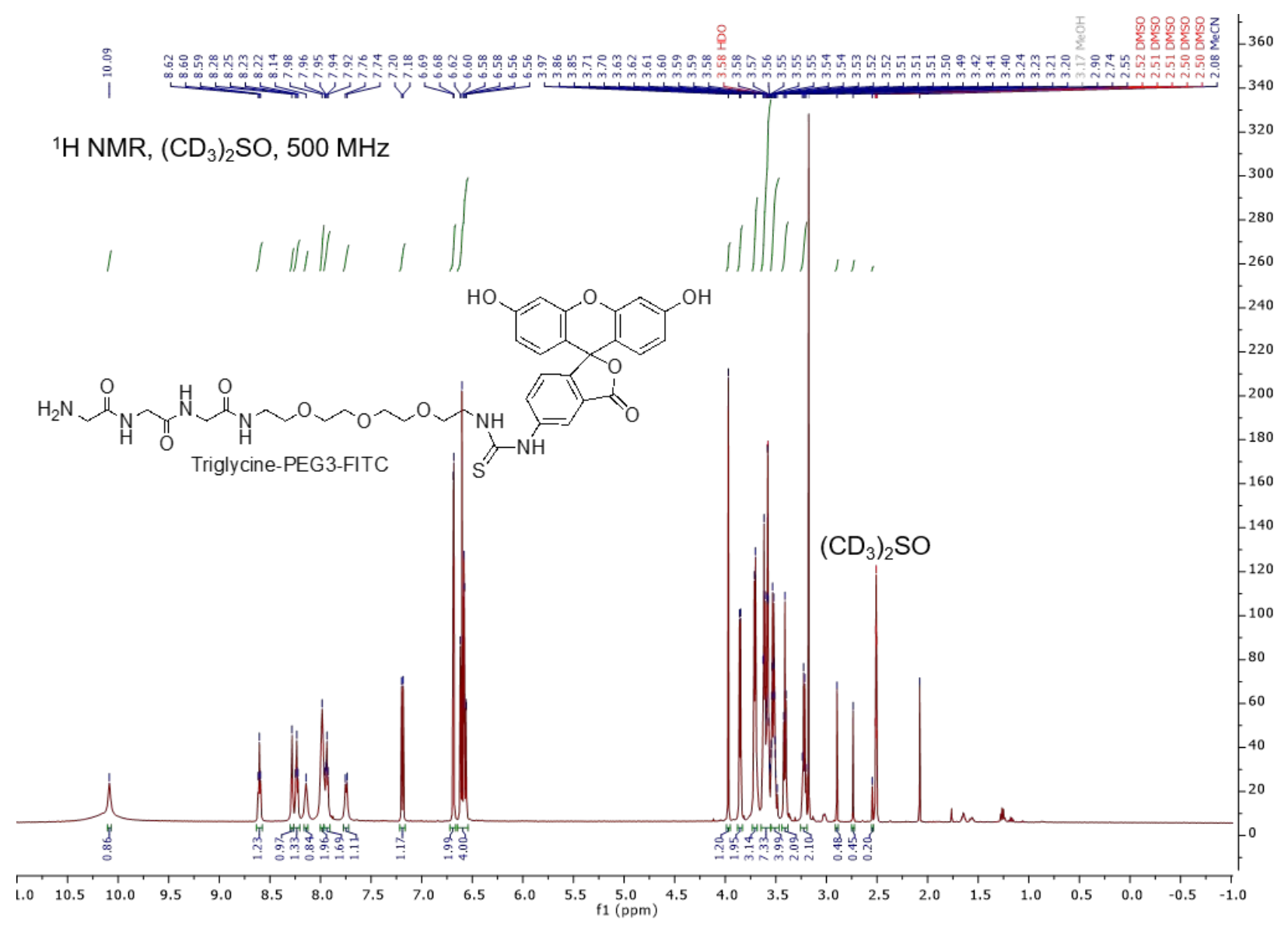

Figure S13. ${ }^{1} \mathrm{H}$ NMR spectrum of triglycine-PEG3-FITC. 


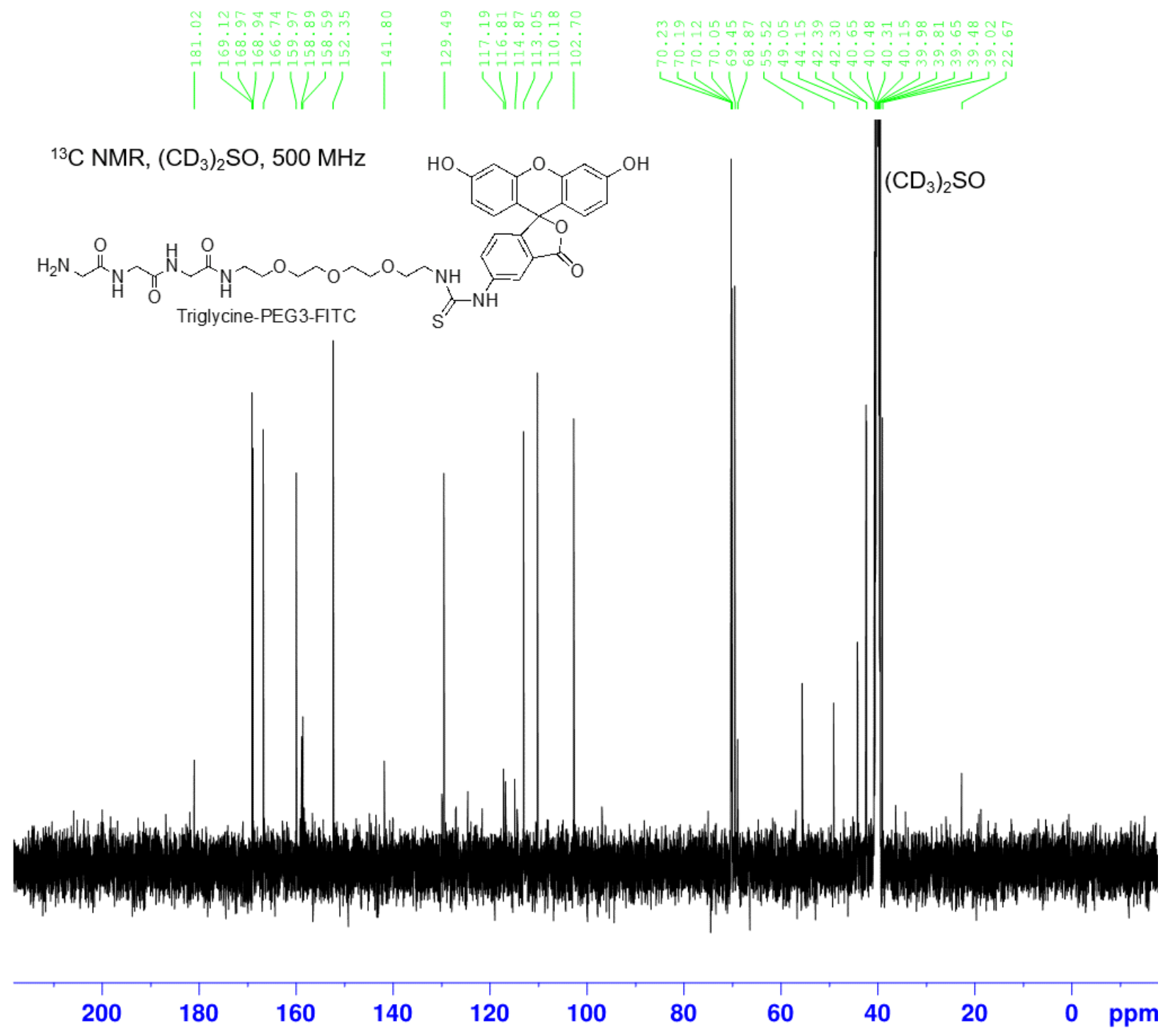

Figure S14. ${ }^{13} \mathrm{C}$ NMR spectrum of triglycine-PEG3-FITC. 
Table S1. Analysis of Fc-FITC UV-Vis spectrophotometry data to determine the degree of Fc-

FITC dye-labeling. All Fc values are per monomer.

\begin{tabular}{lccccccc}
\hline Species & E (protein, 280 nm) & E (dye, max nm) & Dye CF & [mg/ml] & 280 nm Abs. & 490 nm Abs. & Dye/Fc \\
\hline Fc-LPETGGH ${ }_{6}(15 \mathrm{uM})$ & 35785 & NA & NA & 0.41 & 0.549 & 0.002 & 0 \\
FC-FITC $(15 \mathrm{uM})$ & 35785 & 47155 & 0.269 & 0.41 & 0.792 & 0.846 & 1.14 \\
\hline
\end{tabular}




\begin{tabular}{c|ccc}
\multicolumn{4}{c}{ FC-Insulin(2) Yield Comparison P-values } \\
\hline \multirow{3}{*}{ Eq. Insulin } & SML:CUAAC & SML:SPAAC & CUAAC:SPAAC \\
\hline \multirow{2}{*}{2} & $7.9 \mathrm{E}-01$ & $1.9 \mathrm{E}-03$ & $9.7 \mathrm{E}-04$ \\
2 & $2.6 \mathrm{E}-03$ & $5.0 \mathrm{E}-02$ & $9.4 \mathrm{E}-04$ \\
4 & $4.7 \mathrm{E}-04$ & $1.5 \mathrm{E}-04$ & $1.8 \mathrm{E}-02$ \\
8 & $1.9 \mathrm{E}-06$ & $7.4 \mathrm{E}-08$ & $3.3 \mathrm{E}-02$
\end{tabular}

\begin{tabular}{c|ccc}
\multicolumn{4}{c}{ Fc-Insulin(Monomer) Yield Comparison P-values } \\
\hline \multicolumn{4}{c}{} \\
Eg. Insulin & SML:CUAAC & SML:SPAAC & CuAAC:SPAAC \\
\hline $\mathbf{1}$ & $3.0 \mathrm{E}-01$ & $2.0 \mathrm{E}-03$ & $4.9 \mathrm{E}-03$ \\
$\mathbf{2}$ & $3.7 \mathrm{E}-02$ & $7.2 \mathrm{E}-01$ & $1.8 \mathrm{E}-03$ \\
$\mathbf{4}$ & $1.4 \mathrm{E}-03$ & $1.1 \mathrm{E}-03$ & $4.9 \mathrm{E}-01$ \\
$\mathbf{8}$ & $3.2 \mathrm{E}-05$ & $8.9 \mathrm{E}-07$ & $6.0 \mathrm{E}-01$
\end{tabular}
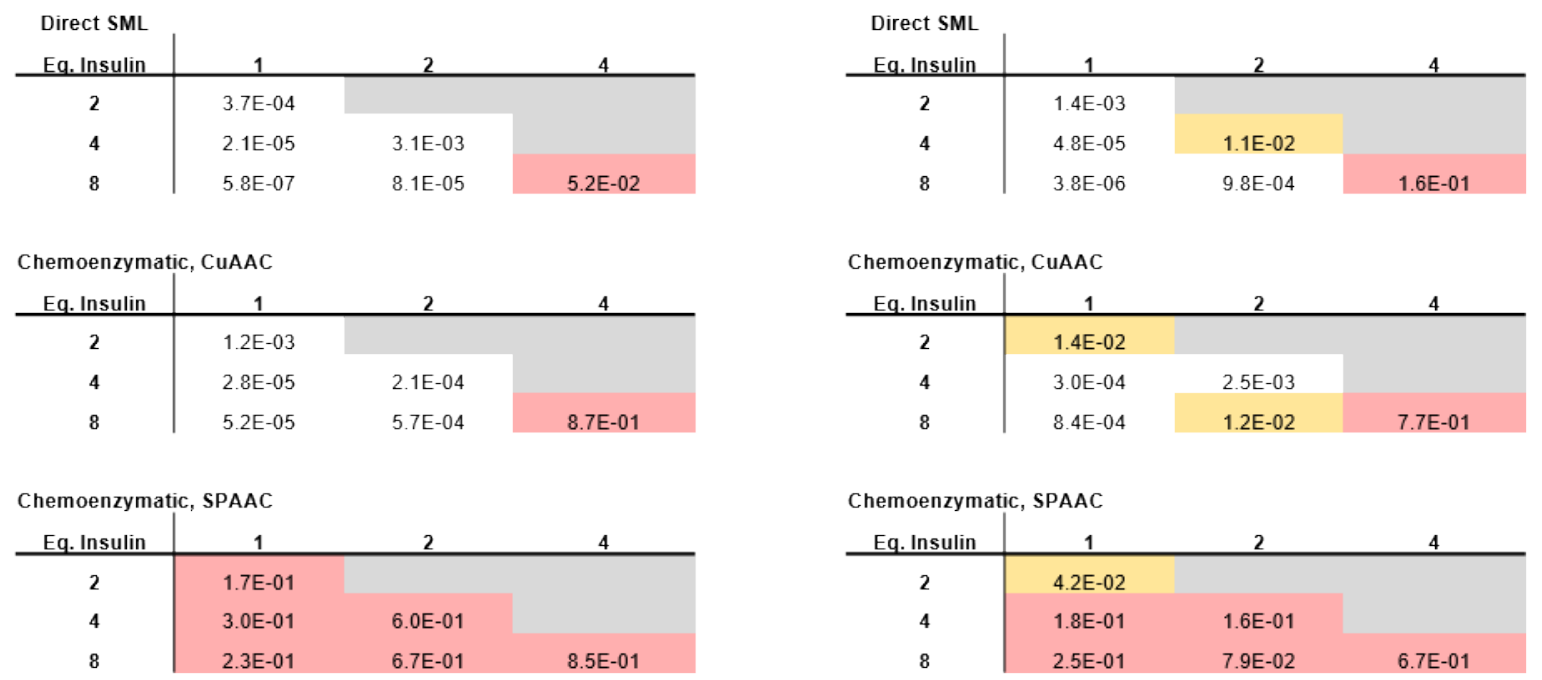

Table S2. P-values for the comparison of Fc-insulin synthetic strategies. Red: $p>0.05$, Yellow:

$0.05>\mathrm{p}>0.005$, White: $\mathrm{p}<0.005$. 


\section{REFERENCES}

1. Wang, B.; DeKosky, B. J.; Timm, M. R.; Lee, J.; Normandin, E.; Misasi, J.; Kong, R.; McDaniel, J. R.; Delidakis, G.; Leigh, K. E.; Niezold, T.; Choi, C. W.; Viox, E. G.; Fahad, A.; Cagigi, A.; Ploquin, A.; Leung, K.; Yang, E. S.; Kong, W.-P.; Voss, W. N.; Schmidt, A. G.; Moody, M. A.; Ambrozak, D. R.; Henry, A. R.; Laboune, F.; Ledgerwood, J. E.; Graham, B. S.; Connors, M.; Douek, D. C.; Sullivan, N. J.; Ellington, A. D.; Mascola, J. R.; Georgiou, G., Functional interrogation and mining of natively paired human VH:VL antibody repertoires. Nat Biotechnol 2018, 36 (2), 152-155.

2. Fahad, A. S.; Timm, M. R.; Madan, B.; Burgomaster, K. E.; Dowd, K. A.; Normandin, E.; Gutiérrez-González, M. F.; Pennington, J. M.; De Souza, M. O.; Henry, A. R.; Laboune, F.; Wang, L.; Ambrozak, D. R.; Gordon, I. J.; Douek, D. C.; Ledgerwood, J. E.; Graham, B. S.; Castilho, L. R.; Pierson, T. C.; Mascola, J. R.; DeKosky, B. J., Functional Profiling of Antibody Immune Repertoires in Convalescent Zika Virus Disease Patients. Front Immunol 2021, 12 (73).

3. Martin, M. M.; Lindqvist, L., The pH dependence of fluorescein fluorescence. Journal of Luminescence 1975, 10(6), 381-390.

4. Chen, I.; Dorr, B. M.; Liu, D. R., A general strategy for the evolution of bond-forming enzymes using yeast display. Proceedings of the National Academy of Sciences 2011, 108 (28), 11399.

5. Carpino, L. A.; Han, G. Y., 9-Fluorenylmethoxycarbonyl amino-protecting group. The Journal of Organic Chemistry 1972, 37 (22), 3404-3409. 